\title{
Acordos no processo administrativo sancionador: solução negociada como uma opção eficiente
}

\author{
Agreements in the sanctioning administrative process: negotiated \\ solution as an efficient option
}

\author{
Valter Shuenquener de Araujo ${ }^{1}$ \\ Ana Letícia da Costa Siqueira ${ }^{2}$ \\ Frederico Silva de Mello ${ }^{3}$
}

\begin{abstract}
RESUMO
O presente trabalho tem por objetivo analisar a viabilidade de utilização de instrumentos consensuais em substituição à aplicação de sanções legalmente previstas na seara sancionadora. A metodologia de pesquisa adotada foi a teórica descritiva e propositiva com a análise de fontes bibliográficas sobre o tema estudado. Para tanto, examina-se o fundamento e a natureza dos acordos substitutivos, assim como os requisitos e limites para a celebração da transação no procedimento administrativo sancionador ou, ainda, em momento anterior à sua propositura.
\end{abstract}

\section{PALAVRAS-CHAVE:}

Direito Administrativo Sancionador, Acordo, Solução negociada, Transação, Processo Administrativo Disciplinar.

\begin{abstract}
The present work aims to analyze the feasibility of using consensual instruments to replace the application of sanctions in the punitive administrative procedure. The research methodology used is theoretical descriptive and bibliographic on the subject studied. For that purpose, it examines the basis and nature of the substitutive agreements, as well as the requirements and limits for entering into the transaction in the administrative sanctioning procedure or, even before the administrative procedure is filed.
\end{abstract}

\section{KEYWORDS:}

Administrative Sanctioning Law, Agreement, Negotiated solution, Transaction, Disciplinary Administrative Procedure.

\footnotetext{
${ }^{1}$ Doutor em Direito Público pela UERJ. Doutorado-Sanduíche pela Ruprecht-Karls Universität de Heidelberg (Alemanha). Professor Associado de Direito Administrativo da Faculdade de Direito da UERJ (Graduação e Pósgraduação stricto sens (mestrado e doutorado). Conselheiro Nacional do Conselho Nacional do Ministério Público por indicação do Supremo Tribunal Federal no biênio de 2015-2017 e 2018-2020. Presidente da Comissão de Defesa dos Direitos Fundamentais (CDDF) no CNMP. Juiz Federal. Professor Instrutor de Cursos de Direito Administrativo no STF, TRF2, PRR2, EMERJ. Juiz Auxiliar e Juiz Instrutor no Supremo Tribunal Federal no período de 2011 a 2014. Juiz Auxiliar no Tribunal Superior Eleitoral no ano de 2015. Ex-Procurador do Estado do Rio de Janeiro. Ex-Procurador Federal. Ex-Advogado Concursado da PETROBRAS. Autor e coordenador do projeto FRIDA: Formulário Nacional de Risco e de Proteção à Vida: um formulário desenvolvido para a prevenção e proteção da mulher vítima de violência doméstica.

${ }^{2}$ Graduanda da faculdade de Direito da UERJ.

${ }^{3}$ Graduando da faculdade de Direito da UERJ.
} 


\section{INTRODUÇÃO: CONSENSUALIDADE NO DIREITO ADMINISTRATIVO}

\subsection{Histórico}

O surgimento do Direito Administrativo no mundo tem como marco as primeiras décadas do século XIX com obras de grande relevância provenientes, principalmente, da França. À época, em que os institutos do Direito Administrativo ainda eram compreendidos essencialmente como ferramentas para legitimar o exercício das funções estatais, começa a surgir uma preocupação com o aprimoramento do controle do poder estatal como forma de tutelar os direitos individuais. ${ }^{4}$

Naquele contexto, preponderava o dogma da legalidade, sendo a lei concebida como a decisão política perfeita e o seu cumprimento, por si só, significaria a satisfação do interesse público. Prevalecia a ideia do ato administrativo unilateral, caracterizado como manifestação da Administração interventiva. ${ }^{5}$

A transição para o modelo de Estado Social acarretou uma maior intervenção estatal no plano socioeconômico, com a sua expansão em dois sentidos: em sua estrutura ${ }^{6}$ e no rol de suas atividades. ${ }^{7}$ Todavia, esse modelo intervencionista também se mostrou falho, ${ }^{8}$ o que estimulou,

\footnotetext{
${ }^{4}$ MEDAUAR, Odete. Direito Administrativo Moderno. 21. ed. Belo Horizonte: Fórum, p. 30, 2018.

${ }^{5}$ BATISTA JÚNIOR, Onofre Alves. CAMPOS, Sarah. A Administração Pública consensual na modernidade líquida. Fórum Administrativo - FA. Belo Horizonte. v. 14, n. 155, p. 31-43, jan. 2014.

6 "Quanto à estrutura, multiplicaram-se os órgãos centrais e realizou-se processo de criação de entes, dotados de personalidade jurídica própria, para atuar em setores específicos. Muitos deles, pela atribuição de personalidade jurídica privada ou pelo fato de realizarem atividades comerciais e industriais, passaram a ter parte da sua atuação disciplinada pelo direito privado". (MEDAUAR, Odete. O Direito Administrativo em evolução. 2. ed. rev., atual., e ampl. São Paulo: Editora Revista dos Tribunais, p. 127, 2003).

7 "Ampliaram-se também as atividades, em virtude das mudanças havidas no modo de atuar do Estado; as inúmeras funções assumidas pelo Estado da segunda metade do século XIX realizaram-se pelos órgãos e entidades da Administração. À burocracia-guardiã segue-se a burocracia prestacional. As atividades tornam-se muito variadas. Ocorre, assim, um enriquecimento das funções e crescente tecnização das atividades, com exigência de recrutamento de pessoas dotadas de conhecimentos especializados". (MEDAUAR, Odete. O Direito Administrativo em evolução. 2. ed. rev., atual., e ampl. São Paulo: Editora Revista dos Tribunais, p. 127, 2003).

8 "Um modelo intervencionista, entretanto, também se mostrou insuficiente perante a conjuntura mundial, especialmente nas últimas décadas. Diversos fatores influenciaram uma nova concepção quanto às funções estatais, tais como: (i) o fenômeno da globalização; (ii) o advento da imprensa e a evolução acelerada dos meios de comunicação, em especial o aumento massivo do acesso à internet; (iii) uma exigência de legitimidade das decisões estatais a partir de uma participação plural e pela democratização dos meios procedimentais de tomadas de decisão; (iv) uma diversificação da categoria dos interesses contrapostos na sociedade; (v) uma exigência crescente de soluções rápidas, eficazes e eficientes para atender às necessidades atuais da sociedade e da economia; entre tantos outros" (NEVES, Cleuler Barbosa das; FERREIRA FILHO, Marcílio da Silva.
} 
no Brasil a partir da segunda metade da década de 1990, uma expressiva guinada no seu foco de atuação. O estado brasileiro abandona progressivamente o papel de executor direto de uma variedade de atribuições, para assumir um maior protagonismo como regulador das atividades econômicas.

Paralelamente à mudança, os novos anseios da sociedade passaram a ser de uma Administração Pública que, ao mesmo tempo, seja transparente e eficaz; participativa e imparcial; legal e eficiente. Nesse cenário, os processos decisórios em um Estado Democrático de Direito devem estar centrados no consenso dos destinatários e com o objetivo de garantir um excelente rendimento. ${ }^{9}$ O modelo de Estado autoritário, que decide com unilateralidade e imperatividade, perde força em prol de uma Administração Pública que busca o consenso e a atuação plural dos agentes envolvidos. Por consequência, a consensualidade é vista como uma das formas possíveis, senão a melhor, a depender do caso concreto, para se alcançar a finalidade pública. $^{10}$

Nesse ambiente de incremento ao diálogo é que surge um amplo espaço para o fortalecimento da tese de viabilidade da transação nos processos administrativos sancionadores.

\section{FUNDAMENTO DA BUSCA POR SOLUÇÕES NEGOCIAIS}

A razão central para a disseminação de soluções consensuais no âmbito da Administração Pública é, sem sombra de dúvidas, a busca pelo seu melhor e mais eficiente funcionamento. $\mathrm{O}$ anseio por uma maior efetividade na gestão da coisa pública tem se tornado prioridade atualmente. Com isso, torna-se necessário criar mecanismos para evitar que a atuação administrativa seja pensada de forma muito restritiva com fundamento em uma ideia

Contrapesos de uma Administração Pública consensual: legalidade versus eficiência. Interesse Público - IP, Belo Horizonte, ano 19, n. 103, p. 49-77, maio/jun. 2017).

${ }^{9}$ MEDAUAR, Odete. O Direito Administrativo em evolução. 2. ed. rev., atual., e ampl. São Paulo: Editora Revista dos Tribunais, p. 133, 2003.

10 NEVES, Cleuler Barbosa das; FERREIRA FILHO, Marcílio da Silva. Contrapesos de uma Administração Pública consensual: legalidade versus eficiência. Interesse Público - IP, Belo Horizonte, ano 19, n. 103, p. 49-77, maio/jun. 2017. 
anacrônica de "vinculação positiva à lei". Essa vinculação não pode criar obstáculos desnecessários para a concretização da finalidade pública de modo eficiente e proporcional. ${ }^{11}$

Desse modo, a aplicação de sanções administrativas como a única alternativa para a diminuição de ilícitos é medida a ser questionada. A tomada de decisão, inclusive em questões disciplinares, deve seguir um procedimento em que haja diálogo com o administrado. Nesse mesmo sentido, Diogo de Figueiredo Moreira Neto sustenta que, mais do que a substituição do modo tradicional de atuação estatal, a consensualidade no Direito Administrativo tem o papel de reduzir distorções que eventuais prerrogativas administrativas podem causar. Em suas palavras:

A consensualidade, por certo, não estará destinada a substituir as formas tradicionais de ação imperativa do Estado, mas, sem dúvida, já representa uma mudança substancial em inúmeras modalidades de atuação, concorrendo para a redução do arbítrio e da conflitualidade, sempre mais frequentes na atuação predominantemente unilateral do Estado. ${ }^{12}$

Ao considerar, portanto, que 'a potestade sancionadora é meramente instrumental às finalidades públicas' e, sendo assim, as mencionadas finalidades públicas 'podem ser satisfeitas de diversas maneiras pelo Poder Público ${ }^{13}{ }^{13}$ é possível perceber que o surgimento dos acordos substitutivos, como alternativa às sanções nos processos administrativos sancionadores, constitui mais uma forma de satisfazer o interesse público, com a particularidade de atender a dinamicidade e pluralidade próprias da sociedade contemporânea.

Noutro giro, o consensualismo na Administração Pública também pode ser justificado como uma forma de se melhor concretizar o princípio da eficiência, haja vista que ele privilegia o melhor instrumento para se alcançar um resultado proveitoso para a sociedade. Cria-se uma nova e eficiente forma de relacionamento da Administração com o infrator.

\footnotetext{
11 "O que devemos buscar, portanto, é que a prevalência dos fins sobre os meios legais esteie uma firme metodologia, que, fincada nos Princípios da Eficiência, Moralidade e Proporcionalidade, minore as possibilidades de ser utilizada contra os fins a que se destina e que, ao mesmo tempo, evite que a aplicação meramente lógico-subsuntiva das regras jurídicas pela mera invocação da legalidade formal, muitas vezes utilizada como biombo de malversações, contrarie os objetivos públicos maiores do ordenamento jurídico" (ARAGÃO, Alexandre Santos de. A Consensualidade no Direito Administrativo: acordos regulatórios e contratos administrativos. Revista de Direito do Estado. v. 1. Rio de Janeiro: Renovar, p. 298, jan./mar. 2006).

${ }^{12}$ MOREIRA NETO, Diogo de Figueiredo. Quatro paradigmas do Direito Administrativo. Belo Horizonte: Fórum, 2008. p. 118/119.

${ }^{13}$ PALMA, Juliana Bonarcosi de. Atuação Administrativa consensual: Estudo dos acordos substitutivos no processo administrativo sancionador. 2010. 332f. Dissertação (Mestrado em Direito) - Faculdade de Direito da Universidade de São Paulo (USP), p. 162, São Paulo.
} 


\subsection{Princípio da Eficiência}

O princípio constitucional da eficiência possui, no dizer de Juliana de Palma, três significados: (i) é sinônimo de boa administração; (ii) trata-se de um comando de otimização de decisões administrativas, e (iii) se apresenta enquanto um dever de escolha do meio mais adequado. $^{14}$

Como sinônimo de boa administração, a expressão nos permite concluir que a Administração Pública deve ser orientada para uma atuação eficaz em que há uma otimização, por parte do gestor, do emprego dos escassos recursos disponíveis. ${ }^{15}$

Por outro lado, a eficiência como comando de otimização de decisões administrativas considera, sobretudo, os resultados da atividade exercida, objetivando a melhor satisfação do interesse público. Sob essa ótica, o princípio da eficiência está relacionado, ainda, ao "exercício da competência administrativa pela Administração ao requisitar a presença de elementos potencializadores de um procedimento mais célere e técnico". ${ }^{16}$

Como dever de escolha do meio mais adequado para determinar decisões eficientes ao caso concreto, a eficiência exige a seleção do instrumento jurídico mais apropriado para a satisfação de uma determinada finalidade pública.

\footnotetext{
${ }^{14}$ PALMA, Juliana Bonarcosi de. Atuação Administrativa consensual: Estudo dos acordos substitutivos no processo administrativo sancionador. 2010. 332f. Dissertação (Mestrado em Direito) - Faculdade de Direito da Universidade de São Paulo (USP), p. 91, São Paulo.

15 "A maior parte das menções à boa administração no Brasil, contudo, correlaciona-se com o dever constitucional de eficiencia. Segundo Moreira Neto, o 'dever de boa administração' decorreria de conjugação dos deveres de eficiência, de economicidade e de 'legitimidade'. Significaria que os atos administrativos realizam seus regulares efeitos jurídicos, mediante aplicação ótima de meios administrativos disponíveis e idôneos, inclusive mediante controle dos resultados pela avaliação de custos e de benefícios, quando possível. Em sentido similar, Freitas conclui que os deveres de eficácia, de eficiência e de economicidade devem servir a uma 'abordagem sistemática do controle dos atos administrativos', promovendo-se a realização, dentre outros, do direito fundamental à 'boa administração', entendida como 'feixe de princípios e regras, como sói acontecer com os direitos fundamentais', ou como "direito fundamental à administração pública eficiente e eficaz, proporcional cumpridora de seus deveres, com transparência, motivação, imparcialidade e respeito à moralidade, à participação social e à plena responsabilidade por suas condutas omissivas e comissivas', composto dos direitos fundamentais à administração pública transparente, à administração pública dialógica, dentre outros" (SILVA, Gabriel Cozendey Pereira. Indefinição conceitual acerca do dever constitucional de eficiência administrativa. Interesse Público - IP, Belo Horizonte, ano 18, n. 96, p. 93-122, mar./abr. 2016).

${ }^{16}$ PALMA, Juliana Bonarcosi de. Atuação Administrativa consensual: Estudo dos acordos substitutivos no processo administrativo sancionador. 2010. 332f. Dissertação (Mestrado em Direito) - Faculdade de Direito da Universidade de São Paulo (USP), p. 92, São Paulo.
} 
Adotando essa vertente, a grande dificuldade paira em torno da escolha do critério a ser utilizado como meio adequado para a determinação de decisões eficientes. Nesse sentido, Juliana de Palma recorre aos critérios utilitarista ${ }^{17}$ e da proporcionalidade. ${ }^{18} \mathrm{E}$ a escolha de qualquer um desses dois critérios demonstra, por si só, a ideia de instrumentalidade do Direito Administrativo. Explica-se: a análise dos institutos jurídicos é realizada de acordo com a finalidade pública a ser por eles satisfeita, abandonando-se o mero formalismo, que pressupõe uma Administração Pública de atuação unilateral, impositiva e centrada na lei, sem se importar com os efeitos práticos das suas decisões.

Nesse cenário de crescimento da funcionalidade do Direito Administrativo, ${ }^{19}$ está, portanto, inserida a consensualidade, a ser prestigiada em razão dos diversos efeitos positivos que ela pode gerar em um caso concreto e, ainda, por ela satisfazer, de forma mais plena, a finalidade pública.

\subsection{Governança Pública}

\footnotetext{
17“Para Bentham (1989), uma medida do governo está de acordo com o princípio da utilidade se promove a maior felicidade da comunidade, mas este interesse é definido simplesmente como a soma dos interesses individuais, a soma dos interesses de cada pessoa que componha esse corpo chamado "comunidade” (...) Dessa maneira, a Nova Gestão Pública parte para a justificativa da contratação, da privatização, da adoção de medidas gerenciais preocupadas com a eficiência no uso dos recursos, mesmo que isto possa soar estranho à Administração Pública, desde que os resultados sejam gerados e estejam de acordo com as necessidades da comunidade." (ZAPELINI, Marcello Beckert. Ética e Administração Pública: Uma abordagem a partir de Três Modelos Normativos. In: XXXVII Encontro da ANPAD. Rio de Janeiro, 7 a 11 de setembro de 2013).

${ }^{18 “ A}$ doutrina identifica como típica manifestação do excesso de poder a violação do princípio da proporcionalidade ou da proibição de excesso (Verhältnismässigkeitsprinzip; Übermassverbot), que se revela mediante contraditoriedade, incongruência e irrazoabilidade ou inadequação entre meios e fins. No direito constitucional alemão, outorga-se ao princípio da proporcionalidade ou ao princípio da proibição de excesso qualidade de norma constitucional não escrita. A utilização do princípio da proporcionalidade ou da proibição de excesso no direito constitucional envolve, como observado, a apreciação da necessidade (Erforderlichkeit) $e$ adequação (Geeignetheit) da providência legislativa" (BRANCO, Paulo Gustavo Gonet; MENDES, Gilmar Ferreira. Curso de Direito Constitucional. 10. ed. São Paulo: Saraiva, p.225, 2015).

19 "Não é descabido inferir que o estudo do ato administrativo propicia uma análise aprofundada da sua própria atuação administrativa; identificar os elementos característicos dos atos administrativos, sua funcionalidade e a atual 'perda de centralismo' em prol de figuras eminentemente consensuais, portanto, mostra-se imprescindivel à compreensão das mutações perpassadas no âmbito do cumprimento das competências administrativas. (...) Paralelamente à clássica atribuição garantística, a funcionalidade do processo administrativo expande-se para abranger também a racionalização das decisões administrativas. Resultado da inserção da eficiência como um dos escopos da atuação administrativa, o processo administrativo". (SCHIRATO, Vitor Rhein; PALMA, Juliana Bonacorsi de. Consenso e legalidade: vinculação da atividade administrativa consensual ao direito. Revista Brasileira de Direito Público - RBDP, Belo Horizonte, ano 7, n. 27, out./dez. 2009. Disponível em: <http://www.bidforum.com.br/PDI0006.aspx?pdiCntd=64611>. Acesso em: 10 dez. 2019).
} 
Um fator de indubitável relevância para a ascensão da consensualidade administrativa é a chamada Governança Pública, definida por Gustavo Justino de Oliveira como:

\footnotetext{
um modelo alternativo a estruturas governamentais hierarquizadas, implicando que os Governos sejam muito mais eficazes em um marco de economia globalizada, não somente atuando com capacidade máxima de gestão, mas também garantindo e respeitando as normas e valores próprios de uma sociedade democrática. ${ }^{20}$
}

A Governança Pública, que deve ser adotada pelo contemporâneo modelo de Estado, expandiu o fenômeno da contratualização na Administração, não somente substituindo a atuação impositiva e unilateral, mas, também, por meio de normas que criam novos tipos contratuais. Nesse ambiente, privilegia-se a utilização dos instrumentos consensuais para a satisfação das finalidades públicas, o que reflete uma nova forma de democracia participativa em que a mediação e o diálogo são fundamentais.

O acordo administrativo ganha uma função de maior destaque em todos os âmbitos da atuação pública, aparecendo, a título exemplificativo, no Decreto-Lei no 3.365/41, que prevê a possibilidade de mediação na desapropriação, ${ }^{21}$ e no art. 17 , parágrafo $1^{\circ}$ da Lei $n^{\circ} 8.429 / 92$, que viabiliza a transação nas ações de improbidade administrativa.

\section{DESAFIOS À TRANSAÇÃO NO DIREITO ADMINISTRATIVO}

O processo administrativo sancionador tem por finalidade imediata a investigação de ilícitos administrativos, a fim de se aplicar a sanção adequada na hipótese de sua ocorrência. E, por envolver a investigação de condutas do suposto infrator, ele possui uma estrutura rígida, que procura assegurar o cumprimento dos princípios constitucionais inerentes ao devido processo legal.

A proteção do administrado é, inclusive, uma das prioridades na tramitação de um processo administrativo. Ao dispor sobre o processo administrativo sancionador na esfera

\footnotetext{
20 OLIVEIRA, Gustavo Justino. Governança Pública e Parcerias do Estado: novas fronteiras do direito administrativo. Revista da Procuradoria Geral, Rio de Janeiro, Edição Especial, p. 114, 2012.

${ }^{21}$ Art. $10-B$ do DL no $3.365 / 41$.
} 
federal, a Lei $\mathrm{n}^{\circ}$ 9.784/1999 estabelece como objetivos substanciais a "proteção dos direitos dos administrados" e o melhor "cumprimento dos fins da Administração".

A consciência sobre o desenho institucional e a função do processo sancionador é importante para se definir a viabilidade dos acordos substitutivos nestes procedimentos. Pois, conforme definido por Celso Antônio Bandeira de Mello, o intuito da proibição de uma conduta administrativa reprovável é "disciplinar a vida em sociedade" e não a punição como finalidade última. $^{22}$

Há, contudo, desafios a serem enfrentados para que a mediação e negociação façam parte da dinâmica do processo administrativo sancionador. Abaixo passamos a analisar alguns aparentes obstáculos frequentemente lembrados.

\subsection{O princípio da legalidade como um aparente obstáculo.}

A aposta no princípio da legalidade como o único parâmetro de conduta da Administração Pública gera o engessamento da atuação pública, inviabilizando o enfrentamento de problemas que surgem em um ambiente de aumento das prioridades estatais, especialmente presente quando se tem um fortalecimento dos direitos sociais.

O panorama do estado intervencionista exigiu uma construção jurídica apta a abranger uma atuação mais dinâmica do Estado. O formalismo excessivo, prejudicial ao avanço social, político e econômico, cede para um modo de agir focado no resultado, mais dinâmico e com maior participação popular. A ideia consubstanciada no princípio da juridicidade administrativa $^{23}$ de que o administrador deve obediência a todo o ordenamento jurídico (atos administrativos, leis, constituição, decisões judiciais etc.), e não apenas às leis, legitima a

\footnotetext{
22 BANDEIRA DE MELlO, Celso Antônio. Curso de direito administrativo. 26. ed. São Paulo: Malheiros, p. 840, 2009); "Por sua vez, Celso Antônio Bandeira de Mello ressalta que a infração administrativa não tem por finalidade causar aflição ou castigo, mas simplesmente busca disciplinar a vida em sociedade para alcançar um bom convívio social. Assim, a infração consiste no "descumprimento voluntário de uma norma administrativa para o qual se prevê sanção cuja imposição é decidida por uma autoridade no exercício de função administrativa - ainda que não necessariamente aplicada nesta esfera" (GUARDIA, Gregório Edoardo Raphael Selingardi. Princípios processuais no Direito Administrativo Sancionador: um estudo à luz das garantias constitucionais. Revista da Faculdade de Direito da USP, São Paulo, v. 109, p. 773-793, jan./dez. 2014).

23 "A atuação da Administração deve ser conforme a lei e o Direito". In: FRANÇA, Vladimir da Rocha. Invalidação administrativa na Lei n. 9.784/99. Revista de Direito Administrativo, Rio de Janeiro, v. 225, p. 225, jul./set. 2001.
} 
conclusão de que a resposta estatal à infração administrativa pode vir por meio de um processo negociado através, inclusive, da mediação. Quanto ao tópico, Marco Antônio Rodrigues comenta como a submissão cega ao princípio da legalidade pode comprometer o funcionamento adequado da Administração Pública, verbis:

\begin{abstract}
No panorama atual brasileiro, é incontroverso que a legalidade administrativa não é, nem pode ser, apenas a submissão estrita da Administração às prescrições, sob pena de a Administração contemporânea ficar atravancada, em razão de eventual ausência de normatização pelo Legislativo. Hoje, a Constituição permite e impõe ao administrador que não fique ao aguardo de uma lei, para que então aja em defesa das previsões constitucionais. A constitucionalização do Direito, acompanhada da força normativa da Constituição, permitem e impulsionam o administrador a tornar efetivas as normas constitucionais em sua maior dimensão possível. Vê-se, portanto, uma mutação do princípio da legalidade administrativa no Direito Administrativo pátrio, que passou a se constituir num princípio de juridicidade, ou de constitucionalidade: a Administração deixa de ser vinculada exclusiva e necessariamente à existência prévia de lei, e passa a se pautar no direito como um todo, e, em especial na Constituição. A vinculação dos atos administrativos não se faz mais com relação exclusivamente à lei, mas à Constituição e demais normas de ordenamento, gerando, outrossim, um novo parâmetro de vinculação do administrador. ${ }^{24}$
\end{abstract}

Nesse contexto de ampliação das atribuições do Estado e de fortalecimento dos princípios constitucionais, a atuação negocial estatal ganha espaço e deve ser considerada legítima para a solução de conflitos entre a Administração e o infrator no âmbito do direito sancionador. ${ }^{25}$ Tal modo de proceder impulsiona as diretrizes da efetividade, eficiência e desenvolvimento social almejadas pelo constituinte. ${ }^{26}$ Alexandre Santos de Aragão chama

\footnotetext{
${ }^{24}$ RODRIGUES, Marco Antônio dos Santos. Neoconstitucionalismo e legalidade administrativa: a juridicidade administrativa e sua relação com os direitos fundamentais. Revista de Direito Procuradoria Geral, Rio de Janeiro, v. 63, p. 195-196, 2008.

${ }^{25}$ ARAUJO, Valter Shuenquener de. Direito Administrativo Sancionador no Brasil: uma contribuição para a efetividade dos direitos fundamentais. In: ARABI, Abhner Youssif Mota; MALUF, Fernando, MACHADO NETO, Marcello Lavenère (Coord.). Constituição da República 30 anos depois: uma análise prática da eficiência dos direitos fundamentais. Estudos em homenagem ao Ministro Luiz Fux. P. 437-438. Belo Horizonte: Fórum, 2018. ISBN: 978-85-450-0598-8.

26 "O nosso entendimento diante da controvérsia é de que não se pode olvidar que as leis não são as únicas fontes de direitos e de obrigações. O ordenamento jurídico deixa espaço livre de autonomia para os sujeitos jurídicos estabelecerem voluntariamente vínculos entre si, com obrigações oriundas, não da lei, mas do acordo de vontades. Ora, não parece adequado sustentar que essa faculdade negocial jusgenética deixe de existir tout court quando uma das partes for o Estado. Em primeiro lugar, como o acordo pressupõe a adesão voluntária do privado, não há invasão da esfera jurídica individual, que pressuporia lei; e em segundo lugar, em sendo assim, não há razão para se retirar do Estado o acordo de vontades como um instrumento que, a par da lei, também se presta à realização dos interesses públicos, caracterizando-se 'o contrato de concessão como uma espécie de fonte de legalidade administrativa inter partes' (VALDEZ, Oscar Aguilar. El acto administrativo regulatorio. Acto administrativo y reglamento. Buenos Aires: Ediciones RAP. 2002. p. 457). 'O acordo de vontades como criador de regras jurídicoadministrativas faz do sujeito ordinário parte ativa da definição e realização do interesse público, cria em primeiro plano verdadeiras relações jurídicas - inclusive de longa duração - baseadas naquelas regras'. (ALFONSO, Luciano Parejo. Los actos administra- tivos consensuales. Revista de Direito Administrativo e Constitucional A \& C, Belo Horizonte, v. 13, 2003, p. 15). O Princípio da Legalidade, mesmo em sua acepção mais rígida, foi elaborado para assegurar a esfera jurídica dos particulares diante de atos imperativos que gerem gravames, não para aqueles que beneficiem o particular ou que se "expressassem em convenções, nas quais o assentimento da outra parte
} 
atenção para o fato de a Administração Pública contemporânea ter de adotar uma postura orientada para a obtenção dos melhores resultados, e não mais focada em um modo de agir meramente legalista, no pior sentido da expressão, verbis:

O que devemos buscar, portanto, é que a prevalência dos fins sobre os meios legais esteie uma firme metodologia, que, fincada nos Princípios da Eficiência, Moralidade e Proporcionalidade, minore as possibilidades de ser utilizada contra os fins a que se destina e que, ao mesmo tempo, evite que a aplicação meramente lógico-subsuntiva das regras jurídicas pela mera invocação da legalidade formal, muitas vezes utilizada como biombo de malversações, contrarie os objetivos públicos maiores do ordenamento jurídico. ${ }^{27}$

Dessa forma, o princípio da legalidade não pode ser um obstáculo aos acordos substitutivos no âmbito dos processos administrativos sancionadores. Considerando que a lei não é a fonte exclusiva de legitimação da atuação estatal, não se mostra justificável invocar a legalidade para impedir a prática negocial em matéria sancionadora. E, por outro lado, nunca é demais lembrarmos que o art. 32 da Lei de Mediação, Lei n 13.140/15, já prevê a possibilidade de a Administração Pública dirimir seus conflitos com particulares por meio da mediação e o dispositivo, ainda, viabiliza a celebração de um termo de ajustamento de conduta pelas partes. ${ }^{28}$ O princípio da legalidade deve, assim, ter como função delimitar as regras sobre a transação, sobretudo no campo da competência dos órgãos públicos para negociar.

\subsection{Ausência da autonomia da vontade na Administração Pública}

A autonomia da vontade é um dos pilares da dinâmica contratual privada. É um instituto próprio da teoria geral dos contratos, no Direito Civil, que permite as partes se manifestarem livremente, de forma a negociar e dispor de seus próprios interesses.

também é idôneo para superar a eficácia do princípio" (GIANNINI, Massimo Severo. Diritto amministrativo. 3. ed. Milano: Giuffrè, 1993. v. 1, p. 89, grifo nosso), até porque, lembremos, tanto a lei como o contrato podem ser fontes de direito" (ARAGÃO, Alexandre Santos de. A Consensualidade no Direito Administrativo: acordos regulatórios e contratos administrativos. Revista de Direito do Estado. v. 1. Rio de Janeiro: Renovar, p. 300, jan./mar. 2006).

${ }^{27}$ ARAGÃO, Alexandre Santos de. A Consensualidade no Direito Administrativo: acordos regulatórios e contratos administrativos. Revista de Direito do Estado, v. 1, Rio de Janeiro, p. 298, jan./mar. 2006.

${ }^{28}$ Art. 32. A União, os Estados, o Distrito Federal e os Municípios poderão criar câmaras de prevenção e resolução administrativa de conflitos, no âmbito dos respectivos órgãos da Advocacia Pública, onde houver, com competência para:

(...) II - avaliar a admissibilidade dos pedidos de resolução de conflitos, por meio de composição, no caso de controvérsia entre particular e pessoa jurídica de direito público;

III - promover, quando couber, a celebração de termo de ajustamento de conduta. 
Ao menos no campo contratual, a autonomia da vontade é elemento essencial justamente por permitir que as partes estipulem os termos do acordo e, com isso, criem a disciplina jurídica a que estarão vinculadas.

Inicialmente, portanto, uma tese no sentido da ausência da autonomia da vontade em relação à Administração Pública impediria o firmamento de acordo, já que não se formaliza uma relação jurídica negocial, sem que haja consenso sobre os moldes do pacto, sem negociação, renúncia e preservação de interesses.

Não é pacífico o entendimento de que a Administração Pública é desprovida de autonomia de vontade. É possível encontrar na literatura jurídica quem defenda a existência de vontade na atuação estatal, ainda que o elemento volitivo não possa ser utilizado isoladamente como critério justificador da tomada de decisão. ${ }^{29}$

Comungamos, contudo, do entendimento de Humberto Ávila sobre esta questão. Entendemos, assim, que a Administração Pública não manifesta a sua vontade de forma completamente autônoma, pois os órgãos que executam as políticas públicas carecem de interesses próprios. ${ }^{30}$ Em verdade, o Estado persegue as finalidades constitucionais e, por meio da execução dos fins instituídos pelas normas jurídicas, regras e princípios, pauta sua conduta, não havendo espaço, portanto, para uma autônoma manifestação de vontade dos entes ou órgãos públicos completamente dissociada dos fins normativos que legitimam a sua atuação.

A ausência de vontade da autoridade estatal não figura, todavia, como óbice à celebração de acordos substitutivos nos processos administrativos sancionadores. A apresentação de uma alternativa à aplicação da sanção administrativas não decorre unicamente da manifestação de

\footnotetext{
29 “A vontade, por si só, não basta para a administração, mas, nem por isso, é possível afirmar, com categoria exclusiva, que o elemento volitivo é inexistente para a administração. A motivação do ato, alicerçada no interesse público, no interesse administrativo, limita a liberdade de contratar. Como ato administrativo, o contrato tem de possuir elementos essenciais (subjetivo, conteúdo-objeto, motivação e finalidade) que, não estando presentes, prejudicam sua validade e eficácia. (...) A vontade, se existente, coaduna-se com o fim último da administração, o interesse público" (SOUZA, Guilherme Carvalho e. A liberdade de contratar para a administração pública: a autonomia da vontade no contrato administrativo. Revista de Direito Administrativo, Rio de Janeiro, v. 260, p. 197, maio/ago. 2012).

30 "Não há dúvida de que a administração não possui autonomia de vontade, mas apenas deve executar a finalidade instituída pelas normas jurídicas constantes na lei dando-lhe ótima aplicação concreta. Por isso a administração não exerce atividade desvinculada, mas apenas exerce, nos fundamentos e limites instituídos pelo Direito, uma função" (ÁVILA, Humberto. Repensando o princípio da supremacia do interesse público sobre o particular. Revista Eletrônica sobre a Reforma do Estado, Salvador, n. 11, p. 2, set./out./nov. 2007).
} 
vontade, mas da necessidade de a Administração alcançar o melhor e mais eficiente resultado juridicamente permitido na sua atuação.

\subsection{Supremacia do interesse público}

O interesse público é, sem dúvidas, um dos principais fundamentos utilizados para rechaçar a transação nos processos administrativos sancionadores. Tendo em vista que a sanção administrativa ainda é erroneamente percebida como uma prerrogativa irrenunciável dos órgãos da administração, e, também, como o único meio para cessar a prática conduta ilícita, sustentar a sua substituição por outro meio parece uma afronta ao interesse público.

Porém, a consideração do interesse público como algo supremo e não sujeito a um juízo de ponderação já é uma premissa questionada independentemente do tema alusivo à possibilidade de mediação no direito sancionador. Na década de 1970, Peter Häberle já sustentava que o interesse privado era um elemento integrante do que se compreende por interesse público, de modo que seria ilógico considerar que um deles poderia entrar em confronto direto com o outro, ou mesmo que um dos dois interesses fosse dotado de um primazia absoluta. ${ }^{31} \mathrm{Na}$ mesma linha, Gustavo Binenbojm sustenta, por exemplo, que a menção à supremacia do interesse público em abstrato é ilógica em razão dos seguintes fundamentos: ${ }^{32}$ há vários interesses públicos relevantes; o respeito a direitos individuais pode representar à satisfação da própria Administração; o interesse público não pode ser confundido com a simples vontade da autoridade pública. ${ }^{33} \mathrm{Com}$ isso, além de criticar a existência de um conteúdo universal e rígido para o denominado interesse público, o citado autor também defende que a efetivação da tese da supremacia acaba por justificar a manutenção de prerrogativas obsoletas.

Nota-se que, independentemente do questionamento quanto ao conteúdo do conceito 'interesse público', não há embasamento suficiente para que o mencionado princípio seja

31 HÄBERLE, Peter. Öffentliches Interesse als juristisches Problem. Eine Analyse von Gesetzgebung und Rechtssprechung. Bad Homburg: Athenäum, 1970.

32 BINENBOJM, Gustavo. Da supremacia do interesse público ao dever de proporcionalidade: um novo paradigma para o Direito Administrativo. Revista de Direito Administrativo, Rio de Janeiro, v. 239, p. 19, jan./mar. 2005.

33 Idem. Parecer sobre exceção do contrato não cumprido solicitado pela Libra Terminal Santos S.A. em litígio com a CODESP, p. 9, 19/02/2018. 
utilizado para impedir a realização dos acordos substitutivos. Isso porque o interesse público não reside unicamente na aplicação de sanções, mas, sobretudo, na efetivação dos valores constitucionais, que servem como diretrizes para a atuação do Estado e a conformação da conduta dos particulares. ${ }^{34}$ Sendo assim, uma vez comprovado que os mecanismos consensuais são capazes de promover o cumprimento das normas, sejam elas de cunho regulatório ou organizacional, o interesse público mostra-se devidamente respeitado. ${ }^{35}$

\section{OS ACORDOS SUBSTITUTIVOS E INTEGRATIVOS}

O acordo substitutivo da sanção prevista para a prática de uma infração é medida capaz de corrigir as distorções promovidas pelo sistema punitivo, especialmente nas circunstâncias em que há, tal como no Brasil, uma superposição excessiva e descoordenada de instâncias de punição. A pena não é um fim em si mesmo. Ela deve desempenhar uma função dissuasória e ter um nítido caráter prospectivo e preventivo, objetivos que também podem ser alcançados por meio da mediação e do acordo na seara sancionadora. Dessa forma, a utilização do consenso

\footnotetext{
34 “No exemplo da prerrogativa sancionatória, um órgão ou ente da Administração Pública pode deixar de aplicar determinada sanção administrativa ou, ainda, findar consensualmente o processo sancionador na medida em que a potestade sancionadora é meramente instrumental às finalidades públicas. Tais finalidades públicas, onde não está compreendida a suposta finalidade repressora do Estado, podem ser satisfeitas de diversas maneiras pelo Poder Público, por meio desde mecanismos notadamente imperativos até mecanismos outros consensuais, nos quais se evidencia a concertação administrativa e a posterior celebração de acordo integrativo ou substitutivo no âmbito do processo administrativo. Cabe à Administração decidir de forma fundamentada a ação administrativa, no âmbito do processo administrativo e com a exposição da escolha deste modo de agir em detrimento de outros" (PALMA, Juliana Bonarcosi de. Atuação Administrativa consensual: Estudo dos acordos substitutivos no processo administrativo sancionador. 2010. 332f. Dissertação (Mestrado em Direito) - Faculdade de Direito da Universidade de São Paulo (USP), p. 162, São Paulo).

35 "Eis porque, ao final das contas, o interesse público poderá efetivamente residir na realização do acordo, e não propriamente na aplicação da sanção. Assim, em uma primeira perspectiva, os princípios de supremacia e de indisponibilidade do interesse público, independentemente de seu conteúdo real (se é que temos), podem apontar exatamente para a realização do acordo (identificado como o interesse público em uma dada situação concreta) e não para a aplicação cega da sanção prevista na regulamentação. Por outro lado, é de se convir que os conceitos de supremacia e indisponibilidade do interesse público não têm contorno capaz de impedir a celebração de acordos substitutivos" (MARQUES NETO, Floriano de Azevedo; CYMBALISTA, Tatiana Matiello. Os acordos substitutivos do procedimento sancionatório e da sanção. Revista Brasileira de Direito Público, Belo Horizonte, ano 8, n. 31, p. 12, out./dez. 2010).
} 
como alternativa às punições previstas nos procedimentos sancionadores permite que se tenha, a depender do caso concreto, mais efetividade na repressão de ilícitos administrativos. ${ }^{36}$

No Direito Brasileiro, considerando a funcionalidade dos institutos, existem basicamente duas categorias de instrumentos consensuais: os acordos substitutivos e os acordos integrativos.

Quanto aos primeiros, Juliana Palma expõe que:

Os acordos substitutivos caracterizam-se pelo efeito terminativo do processo administrativo do qual são celebrados. Quando firmados, estes acordos substituem a decisão unilateral e imperativa da Administração Pública ou findam o processo instaurado para conformação do provimento administrativo. ${ }^{37}$

Esses acordos (substitutivos) podem ser firmados por iniciativa da própria Administração Pública ou mediante provocação do interessado. ${ }^{38}$ Pode ocorrer, ainda, em três diferentes momentos: antes do próprio curso do processo administrativo, de modo a impedir a sua instauração; durante o processo, acarretando a suspensão do seu trâmite até o cumprimento dos termos, ou ao final do processo administrativo, de modo a substituir a sanção administrativa prevista para a infração praticada.

Quanto aos acordos integrativos, recorrendo mais uma vez a Juliana Palma:

Não encerram o processo administrativo no qual são celebrados, pois voltados à viabilização da emissão pela Administração Pública do ato final, imperativo e unilateral, de forma mais célere ou mais adequado às especificidades do caso

\footnotetext{
36 “A Lei 10.233/2001 não contempla expressa vedação à celebração de acordo substitutivo ao processo sancionador. Trata-se de instrumento regulatório alternativo ao processo sancionatório ao prevenir longas contendas administrativas e judiciais acerca das infrações cometidas pelo concessionário que poderão resultar ou não em aplicação de penalidades na medida desejada pela Agência reguladora. Fomenta, assim, a adesão do concessionário ao compromisso de ajustar sua conduta às exigências do contrato e da lei. Nessa perspectiva, as sanções previstas no artigo 78-A da Lei nº 10.233/2001 (advertência, multa, suspensão, cassação, declaração de inidoneidade e perdimento de veículo) assumem caráter instrumental e não um fim em si mesmo, pois, ao visarem à repressão e à prevenção de condutas violadoras das regras do contrato de concessão e da legislação de regência, têm em mira o restabelecimento da adequada prestação dos serviços públicos delegados e não a mera satisfação de pretensão arrecadatória. Dessa forma, a dispor sobre procedimento administrativo para apuração de responsabilidade por violação ao contrato de concessão e à legislação regulatória, o artigo 16 da Resolução ANTT $n^{\circ}$ 442, de 17 de fevereiro de 2004, atualmente regulamentada pela Resolução 5.083, de 27 de abril de 2016, previu a possibilidade de a Agência reguladora celebrar com os concessionários acordos substitutivos aos processos sancionatórios: [...]" (BRAZIL, Tribunal de Contas da União. Acórdão n ${ }^{\circ}$ 2.533/2017. Plenário. Relator: Walton Alencar Rodrigues. Sessão de 14/11/2017. Diário Oficial da União, Brasília, DF).

37 PALMA, Juliana Bonarcosi de. Atuação Administrativa consensual: Estudo dos acordos substitutivos no processo administrativo sancionador. 2010. 332f. Dissertação (Mestrado em Direito) - Faculdade de Direito da Universidade de São Paulo (USP), p. 191, São Paulo.

${ }^{38}$ MOREIRA NETO, Diogo de Figueiredo. Novos institutos consensuais da ação administrativa. Revista de Direito Administrativo. Rio de Janeiro, v. 231, p. 153, jan./mar. 2003.
} 
concreto. De forma bastante simplificada, nesta dinâmica consensual os provimentos administrativos vinculam-se à celebração de acordos administrativos, sem que estes encerrem o processo administrativo, ou seja, a emissão do ato administrativo final condiciona-se à celebração de acordos integrativos. Os acordos administrativos comportam-se, portanto, como atos processuais não terminativos" 39

Nesse sentido, a celebração de acordos integrativos não resulta no término consensual do conflito. Um exemplo é o instituto da leniência, um ajuste que pode ser acostado ao processo administrativo com o objetivo de facilitar a instrução processual. A partir dele, a autoridade pública obterá provas, tornando mais célere o procedimento e facilitando a aplicação de eventual sanção. ${ }^{40}$

\section{REQUISITOS PARA A VALIDADE DE UM ACORDO NO ÂMBITO DO DIREITO ADMINISTRATIVO SANCIONADOR}

A possibilidade de celebração de um acordo no âmbito do direito sancionador não significa a ausência de limites para se alcançar este resultado. É preciso, nesta altura, comentar dois aspectos específicos a serem observadas pelo administrador que se aproxima do infrator para, em um ambiente de mediação ou de negociação, buscar o acordo como a solução mais eficiente e justa em lugar da aplicação da sanção.

\subsection{Possibilidade de acordo ainda que a sanção seja a mais branda.}

Independentemente da gravidade da conduta e da intensidade da sanção, o acordo deve ser admitido. Como mencionado em tópicos anteriores, os procedimentos disciplinares têm por função restabelecer a ordem, o que não significa, necessariamente, aplicar alguma sanção administrativa. Nos casos em que a infração tiver um baixo potencial de causar danos, o ambiente é propício para que o acordo substitutivo seja celebrado, e até mesmo antes da

\footnotetext{
39 PALMA, Juliana Bonarcosi de. Atuação Administrativa consensual: Estudo dos acordos substitutivos no processo administrativo sancionador. 2010. 332f. Dissertação (Mestrado em Direito) - Faculdade de Direito da Universidade de São Paulo (USP), p. 191, São Paulo.

${ }^{40}$ MARRARA, Thiago. Acordos de Leniência no Processo Administrativo Brasileiro: Modalidades, Regime Jurídico e Problemas Emergentes. Revista Digital de Direito Administrativo, v. 2, n. 2, p. 509-527, 3 jul. 2015.
} 
instauração do processo administrativo sancionador. ${ }^{41} \mathrm{O}$ custo total para a conclusão de um processo administrativo disciplinar e a celeridade do acordo para encerrar a controvérsia são aspectos que estimulam inequivocamente a solução consensual.

Como exemplo concreto, a Lei $\mathrm{n}^{\mathrm{o}} 3.278 / 2008$ do estado do Amazonas institui tal possibilidade para procedimentos disciplinares dos servidores da área da segurança em que a pena seja leve. ${ }^{42}$ Ainda, com redação semelhante, o Projeto de Lei $n^{\circ}$ 1.952/07 buscou instituir o mesmo procedimento para o regime disciplinar da Polícia Federal. ${ }^{43}$

\subsection{Homologação pela autoridade superior.}

A homologação administrativa dos acordos substitutivos, a ser realizada por autoridade superior àquele responsável pela mediação e obtenção do acordo, é medida fundamental para o efetivo controle da juridicidade do ato praticado. As normas sobre o tema devem estipular que todo o procedimento destinado à obtenção do acordo em um caso concreto deve ser submetido ao controle posterior para a aferição dos termos do pacto com o ordenamento jurídico.

\footnotetext{
41 "Em face do custo financeiro do processo administrativo disciplinar e dos elevados cometimentos de infrações disciplinares que podem ser definidas como de menor potencial ofensivo, o termo de ajustamento de conduta pode constituir instrumento relevante e alternativo à prévia instauração do processo administrativo disciplinar. Partindose da leitura das leis orgânicas de todos os ramos do Ministério Público brasileiro, bem como da Lei n ${ }^{\circ}$ 8.112/90, infere-se que são tipificadas diversas hipóteses em que a inobservância da norma legal implica na aplicação de reprimenda disciplinar. A medida (grau) da responsabilidade administrativa está diretamente relacionada à natureza do ilícito funcional. Nesse sentido, as infrações leves, apenadas com advertência, podem ser enquadradas como infrações de menor potencial ofensivo" (Justificação da Proposta de Resolução com o propósito de instituir a possibilidade de celebração de Termo de Ajustamento de Conduta - TAC, no âmbito do Ministério Público brasileiro, no exercício do poder disciplinar, 15.5.2018).

${ }^{42}$ Lei estadual no 3.278 de 2008 - Institui regime disciplinar dos servidores do Sistema de Segurança Pública do Estado do Amazonas. Da Transação Administrativa Disciplinar. Art. 53. O superior hierárquico ao tomar conhecimento da ocorrência de fato que configure hipótese de transgressão administrativa de natureza leve, punível com advertência, ou de natureza média, cuja pena máxima cominada seja igual ou inferior a dez dias de suspensão, intimará o suposto autor, podendo propor a ele por meio de Transação Administrativa Disciplinar que se comprometa a não incidir em nova conduta infracional e, se for o caso, a reparar o dano que tenha causado ao erário.

${ }^{43}$ Projeto de Lei $n^{\circ}$ 1.952/07 do Poder Executivo na tentativa de instituir regime disciplinar do Departamento de Polícia Federal em todas as unidades da Federação, e da Polícia Civil do Distrito Federal. Seção III. Da Transação Administrativa Disciplinar. Art. 26. A autoridade competente que tomar conhecimento da ocorrência de fato que configure hipótese de transgressão administrativa de natureza leve, punível com advertência, ou de natureza média, cuja pena máxima cominada seja igual ou inferior a dez dias de suspensão, intimará o suposto autor, podendo propor a ele que se comprometa a não incidir em nova conduta infracional e, se for o caso, a reparar o dano que tenha causado ao erário.
} 
Tanto a Lei $n^{\text {o } 3.278 / 2008 ~ d o ~ e s t a d o ~ d o ~ A m a z o n a s ~}{ }^{44}$ quanto o Projeto de Lei $n^{\circ}$ 1.952/07, ${ }^{45}$ mencionados acima, estipulam a necessidade de homologação por autoridades superiores. Além disso, a Instrução Normativa n. 2/2017 também prevê condicionamento semelhante. ${ }^{46}$

\subsection{Competência para transacionar.}

Em primeiro lugar, cumpre ressaltar que não há uma norma nacional ou geral norma tratando especificamente sobre competência dos entes públicos para transacionar. ${ }^{47}$ Dessa forma, a competência para firmar acordos substitutivos deve ser atribuída para cada órgão ou entidade específica. Em linhas gerais, o órgão com competência para aplicar a sanção deve ter os poderes para negociar com o infrator, sem prejuízo da possibilidade de delegação dessa competência pelo ordenamento jurídico. É desejável que a titularidade para essa atribuição esteja prevista em norma jurídica própria. ${ }^{48}$

\footnotetext{
${ }^{44}$ Projeto de Lei $\mathrm{n}^{\circ}$ 1.952/07 do Poder Executivo na tentativa de instituir regime disciplinar do Departamento de Polícia Federal em todas as unidades da Federação, e da Polícia Civil do Distrito Federal. Seção III. Da Transação

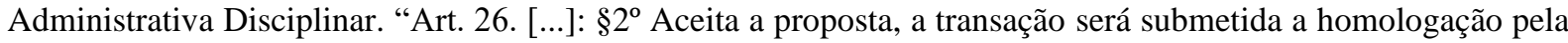
autoridade superior. $\S 3^{\circ}$ Homologada a transação, não será instaurado outro procedimento disciplinar".

${ }^{45}$ Lei estadual no 3.278 de 2008 - Institui regime disciplinar dos servidores do Sistema de Segurança Pública do Estado do Amazonas. 2. Aceita a proposta, a transação será submetida à Corregedoria Geral para análise e, se for o caso, homologação. 3. Homologada a transação, não será instaurado procedimento disciplinar.

${ }^{46}$ Art. $3^{\circ}$ A celebração do TAC será realizada pela autoridade competente para a instauração do respectivo procedimento disciplinar. Parágrafo único. O TAC deverá ser homologado pela autoridade competente para aplicação da penalidade de advertência.

47 “Na há uma regra geral no direito brasileiro determinante da competência dos órgãos e entidades administrativas para a realização de acordos administrativos. Entretanto, é possível elencar, entre diversas autorizações legais, (i) o art. 10 do Decreto-Lei $n^{\circ}$ 3.365/41, segundo o qual 'a desapropriação deverá efetivar-se mediante acordo ou intentar-se judicialmente...'; (ii) o compromisso de ajustamento de conduta, previsto no $\S 6^{\circ}$ do art. $5^{\circ}$ da Lei Federal n ${ }^{\circ} 7.347 / 85$ (Ação Civil Pública); (iii) os acordos no âmbito da execução dos contratos administrativos, nos termos da Lei Federal $n^{\circ}$ 8.666/93, 8.987/95, 11.079/04 e 11.107/05;49 (iv) o compromisso de cessação de prática sob investigação, nos processos em trâmite na órbita do CADE (art. 53 da Lei Federal no 8.884/ 94), e (v) o contrato de gestão, previsto no $\S 8^{\circ}$ do art. 37 da Constituição de 1988 (preceito inserido com a EC no 19/98)" (OLIVEIRA, Gustavo Henrique Justino de; SCHWANKA, Cristiane. A Administração Consensual como a Nova Face da Administração Pública no Século XXI: fundamentos dogmáticos, formas de expressão e instrumentos de ação. Revista de Direito do Estado, v. 10. Rio de Janeiro: Renovar, p. 46, abr./jun. 2008).

48 "A atuação administrativa consensual condiciona-se, portanto, à previsão do acordo administrativo como mecanismo de satisfação das finalidades públicas. Para tanto, basta a determinação da regra de competência para transacionar as prerrogativas públicas para que o Poder Público encontre-se legitimado a terminar consensualmente o processo administrativo em detrimento da atuação administrativa típica. Há na seara da consensualidade reserva de norma para a atuação administrativa por meio de acordos quando a lei formal não preveja a competência para celebrar acordos administrativos. Assim, a atuação administrativa consensual é possível quando houver expressa autorização legal, mesmo que o ente administrativo não disponha de regulamento para versar sobre a dinâmica do instrumento concertado" (PALMA, Juliana Bonarcosi de. Atuação Administrativa
} 
Os acordos substitutivos são geralmente realizados por meio dos Termos de Ajustamento de Conduta (TAC). Como exemplo, a Instrução Normativa n ${ }^{\circ}$ 2/2017 da CGU autoriza a celebração de um TAC nos casos de "infrações disciplinares de menor potencial ofensivo" e estabelece que a competência para firmar o ajuste é da mesma autoridade apta a instaurar o procedimento disciplinar. ${ }^{49}$ A competência para iniciar o processo administrativo disciplinar, por sua vez, é definida por meio de atos normativos secundários ou por meio do regimento interno da instituição. ${ }^{50}$

\section{DO ESPAÇO DECISÓRIO DA ADMINISTRAÇÃo PÚBLICA PARA DECIDIR SOBRE A PROPOSTA DE ACORDO}

Muito embora não haja um direito subjetivo do infrator ao recebimento de uma proposta de transação quanto à infração, a Administração Pública não detém uma ampla discricionariedade para decidir se irá ou não propor um acordo. As circunstâncias do caso concreto, em especial os custos do processo, a gravidade da sanção, os efeitos sistêmicos e

consensual: Estudo dos acordos substitutivos no processo administrativo sancionador. 2010. 332f. Dissertação (Mestrado em Direito) - Faculdade de Direito da Universidade de São Paulo (USP), São Paulo, p. 282, 2010).

${ }^{49}$ Instrução Normativa n. 2, de 30 de maio 2017. Art. $3^{\circ}$ A celebração do TAC será realizada pela autoridade competente para instauração do respectivo procedimento disciplinar.

50 "A norma prevê competências distintas para a celebração e para a homologação do TAC. $\mathrm{O}$ art. $3^{\circ}$ define que a celebração será com a autoridade competente para instauração do respectivo processo disciplinar. A responsabilidade para homologação é atribuída à autoridade competente para a aplicação da penalidade de advertência. Art. $3^{\circ}$ A celebração do TAC será realizada pela autoridade competente para instauração do respectivo procedimento disciplinar. Parágrafo único. O TAC deverá ser homologado pela autoridade competente para aplicação da penalidade de advertência. Diante do silêncio da Lei $n^{\circ} 8.112 / 90$, a competência para instaurar os procedimentos disciplinares no âmbito da Administração Pública Federal depende de regulamentação da matéria, normalmente através do regimento interno do órgão. Assim, autoridade que a norma designar como competente para instauração de processo disciplinar será competente para a celebração do TAC. A competência para instauração do processo disciplinar recai, em princípio, sobre a autoridade titular da competência para impor a sanção administrativa. Mas é possível que a lei ou o regulamento dissociem as duas competências, respeitando-se a regra do art. 141 da Lei $n .8 .112 / 90$ (que dispõe genericamente sobre o assunto) (JUSTEN FILHO, Marçal. Curso de direito administrativo. 12a ed. São Paulo: Revista dos Tribunais, 2016. p. 1373). De forma distinta, a competência para aplicação da penalidade de advertência está prevista no art. 141 da Lei n. 8.112/90, inciso III: chefe da repartição e outras autoridades previstas no regimento interno ou regulamento. Assim, essa autoridade terá a competência para homologação do TAC." (BALINSK, Ricardo. O termo de ajustamento de conduta no processo administrativo disciplinar. 2018. 81 f. Monografia (Graduação em Direito). Faculdade de Direito da Universidade Federal do Rio Grande do Sul (UFRGS), p. 58-59 Porto Alegre). 
dissuasórios decorrentes um célere acordo, podem acabar vinculando a Administração no sentido da propositura das condições do acordo.

Sob outro enfoque, além da necessidade de se motivar a escolha pelo acordo substitutivo, exige-se do infrator, por outro lado, que ele assuma obrigações que, como regra, não assumiria. De acordo com a análise do Tribunal de Contas da União, o desestímulo a novas transgressões somente ocorrerá com acordos capazes de impor obrigações extraordinárias de semelhante intensidade que a da sanção originalmente prevista, impedindo-se, assim, a utilização dos mecanismos consensuais como meio de enriquecimento ilícito ou de incentivo à impunidade. ${ }^{51}$ Significa dizer que cabe à Administração Pública decidir se pretende valer-se desse remédio alternativo no caso concreto, ausente, a princípio, um direito subjetivo público do sancionado ao recebimento da proposta de acordo. ${ }^{52}$

\footnotetext{
51 "Muito se pondera que o termo de ajustamento de conduta previsto no $\S 6^{\circ}$ do artigo $5^{\circ}$ da Lei $n^{\circ} 7.347 / 1985$ seja considerado instrumento típico de prevenção ou de encerramento de litígios judiciais que possam resultar do manejo de ação civil pública. No entanto, nada impede que o mesmo remédio jurídico também seja utilizado em processo de apuração da responsabilidade por descumprimento de contrato e da legislação regulatória, instaurado no âmbito da Agência reguladora, como forma de prevenir contendas administrativas e judiciais acerca de temas tutelados pelo referido diploma legal. Aliás, não há qualquer disposição expressa da Lei de Ação Civil Pública que vincule a celebração do acordo substitutivo sancionador à exclusiva finalidade de prevenção ou encerramento lide judicial que possa resultar do ajuizamento de ação civil pública pela entidade legitimada. Muito menos exige a norma legal que o bem jurídico por ela tutelado no acordo de ajustamento de conduta, no caso, interesse difuso dos usuários dos serviços públicos delegados, seja apreendido de forma imediata sem a mediação de qualquer outro instrumento como é o contrato de concessão. [....] O instrumento consensual não pode, todavia, ser utilizado indiscriminadamente, a ponto de desvirtuar o contrato de concessão pela alteração de metas pactuadas no termo de ajuste, sob pena de frustrar o certame licitatório que deu origem à outorga do objeto. A celebração de TAC's não é, também, expediente para estimular a impunidade pela inadimplência contumaz do concessionário infrator nem gerar reforço negativo quanto à possibilidade de enriquecimento ilícito pelos operadores privados à revelia da legislação regulatória. Dessa forma, a escolha pelo acordo substitutivo não pode ser realizada à custa de mera assunção ou diminuição das obrigações ordinárias já estabelecidas em contrato de concessão, mas deve estar fundada no compromisso de o concessionário assumir obrigações extraordinárias, seja, por exemplo, sob a forma de investimentos suplementares na melhoria e atualização tecnológica do serviço, seja na diminuição das tarifas. Assim, tais compensações haverão de contribuir para melhoria dos serviços regulados, além de desestimular o concessionário a incorrer em futuras transgressões da avença e da legislação regulatória" (BRASIL, Tribunal de Contas da União. Acórdão no 2.533/2017. Plenário. Relator: Walton Alencar Rodrigues. Sessão de 14/11/2017. Diário Oficial da União, Brasília, DF).

${ }^{5}$ Nesse sentido, PALMA, Juliana Bonarcosi de. Atuação Administrativa consensual: Estudo dos acordos substitutivos no processo administrativo sancionador. 2010. 332f. Dissertação (Mestrado em Direito) - Faculdade de Direito da Universidade de São Paulo (USP), p. 162, São Paulo. Na jurisprudência, o TRF da $2^{\text {a }}$ Região já decidiu, nos seguintes termos: “Com relação à alegada violação do princípio da boa-fé, em razão da não realização do Termo de Compromisso de Ajuste de Conduta para suspender a cobrança da multa aplicada, esta não merece acolhida, haja vista ser tal modalidade de acordo prerrogativa da Administração, não gerando direito subjetivo ao administrado a sua realização. De qualquer modo, a não celebração do TCAC, no presente caso, deve-se ao fato de que a Apelante havia regularizado suas atividades junto a ANS antes de se candidatar à celebração do referido ajuste, conforme se depreende do documento de fls. 80/81". TRF-2, 6a Turma, AC n. 0132722-04.2015.4.02.5101, Rel. Des. Poul Erik Dyrlund, j. 30/08/2017.
} 
Como é possível perceber, a iniciativa para o acordo substitutivo é prerrogativa do ente ou órgão administrativo a ser exercida com responsabilidade, com amparo em parâmetros gerais e isonômicos e de modo a desestimular infrações futuras.

\section{CONTROLE JUDICIAL DOS ACORDOS SUBSTITUTIVOS}

Os acordos administrativos resultam de um processo em que as partes dialogam para a construção das cláusulas e condições capazes de originar a solução mais adequada à superação do problema em concreto.

Nos últimos tempos, tem ocorrido uma tendência de aumento do controle jurisdicional dos atos administrativos como uma consequência da própria ampliação do conceito de legalidade e da redução do espaço do mérito administrativo. Por força do art. $5^{\circ}, \mathrm{XXXV}$, da Constituição de 1988, o Poder Judiciário poderá controlar a forma e conteúdo dos acordos firmados no âmbito do direito administrativo sancionador negociado. Entretanto, a postura do juiz deve ser de maior deferência à atuação administrativa, especialmente diante do resultado consensual em que o administrador consentiu com as condições que lhe foram impostas.

Até mesmo por razões de capacidade institucional, o foco do juiz não deve ser na análise da solução estatal mais eficiente ao caso concreto. ${ }^{53}$ Deve, ao revés, aferir se ocorreu o cumprimento do devido processo administrativo que deu origem ao acordo, verificar se há uma

\footnotetext{
53 "Em razão das diversas teorias normativas sobre a função judicial, o argumento das capacidades institucionais considera as habilidades e limitações do Judiciário para concluir que as decisões proferidas por 'juizes reais' (second-best) podem se sair melhor aplicando teorias que não levariam aos resultados mais justos e mais precisos em condições 'ideais' (first-best), que pressupõem, por exemplo, tempo e recursos infinitos, imparcialidade absoluta, capacidade intelectual e conhecimento jurídico sobre-humanos. Em síntese: revela-se necessária a inserção no debate dos argumentos institucionais para se definir o papel ativista ou de contenção do Judiciário. A relativização da supremacia judicial, que pressupõe o Judiciário como intérprete final do ordenamento jurídico, e a abertura ao diálogo entre os Poderes são justificadas pela limitação da capacidade institucional do Poder Judiciário para decidir assuntos técnicos complexos e avaliar os efeitos sistêmicos de suas decisões" (OLIVEIRA, Rafael Carvalho Rezende. Agências reguladoras, diálogos institucionais e controle. Revista de Direito Público da Economia-RDPE, Belo Horizonte, ano 13, n. 49, p. 159-189, jan./mar. 2015).
} 
desproporcional incompatibilidade das cláusulas do acordo com o ordenamento jurídico, bem como se direitos de terceiros foram violados com o pacto. ${ }^{54}$

\section{CONCLUSÕES}

O Direito Administrativo contemporâneo está passando pelos mais variados processos de transformação, e uma das principais mudanças está relacionada à necessidade de se privilegiar uma atuação administrativa eficaz e amplamente conectada com a sociedade, o que implica a desconstrução de dogmas tradicionais da disciplina.

Nesse contexto, a consensualidade mostra-se um mecanismo essencial para apresentar respostas eficazes a condutas ilícitas, garantindo, também, a qualidade da decisão administrativa e acarretando um aumento na probabilidade do seu cumprimento pelo particular. A racionalidade do regime jurídico sancionador é mais facilmente encontrada quando o aplicador da sanção tem, à sua disposição, não meramente a pena, mas outras formas de dissuadir o infrator a não mais praticar a conduta ilícita. No direito sancionador, o diálogo permite uma resposta estatal mais eficiente, mais justa e orientada para a prevenção, características que justificam um aprofundamento maior do estudo da negociação nesse âmbito.

O desafio do futuro é termos balizas e parâmetros gerais capazes de estimular a disseminação do direito administrativo sancionador negociado. $\mathrm{O}$ avanço no estudo do tema impactará na celeridade e economicidade dos processos administrativos e produzirá, seguramente, decisões punitivas com maior qualidade e mais fáceis de serem cumpridas.

\footnotetext{
54 PALMA, Juliana Bonarcosi de. Atuação Administrativa consensual: Estudo dos acordos substitutivos no processo administrativo sancionador. 2010. 332f. Dissertação (Mestrado em Direito) - Faculdade de Direito da Universidade de São Paulo (USP), p. 300-301, São Paulo.
} 


\section{REFERÊNCIAS}

ARAGÃO, Alexandre Santos de. A Consensualidade no Direito Administrativo: acordos regulatórios e contratos administrativos. Revista de Direito do Estado. v. 1. Rio de Janeiro: Renovar, jan./mar. 2006.

ARAUJO, Valter Shuenquener de. Direito Administrativo Sancionador no Brasil: uma contribuição para a efetividade dos direitos fundamentais. In: ARABI, Abhner Youssif Mota; MALUF, Fernando, MACHADO NETO, Marcello Lavenère (Coord.). Constituição da República 30 anos depois: uma análise prática da eficiência dos direitos fundamentais. Estudos em homenagem ao Ministro Luiz Fux. P. 437-438. Belo Horizonte: Fórum, 2018. ISBN: 97885-450-0598-8.

ÁVILA, Humberto. Repensando o princípio da supremacia do interesse público sobre o particular. Revista Eletrônica sobre a Reforma do Estado, Salvador, n. 11, set./out./nov. 2007.

BALINSK, RICARDO. O termo de ajustamento de conduta no processo administrativo disciplinar. 2018. 81 f. Monografia (Graduação em Direito). Faculdade de Direito da Universidade Federal do Rio Grande do Sul (UFRGS), Porto Alegre.

BANDEIRA DE MELLO, Celso Antônio. Curso de direito administrativo. 26. ed. São Paulo: Malheiros, 2009.

BATISTA JÚNIOR, Onofre Alves. Princípio Constitucional da Eficiência Administrativa. Belo Horizonte: Mandamentos, 2004.

BATISTA JÚNIOR, Onofre Alves. CAMPOS, Sarah. A Administração Pública consensual na modernidade líquida. Fórum Administrativo - FA. Belo Horizonte. v. 14, n. 155, jan. 2014.

BRANCO, Paulo Gustavo Gonet; MENDES, Gilmar Ferreira. Curso de Direito Constitucional. 10. ed. São Paulo: Saraiva, 2015.

BRAZIL, Cartilha de licenciamento ambiental. $2^{\mathrm{a}}$ ed., Brasília: Tribunal de Contas da União, Secretaria de Fiscalização de Obras e Patrimônio da União, 2007.

BRAZIL, Justificação da Proposta de Resolução com o propósito de instituir a possibilidade de celebração de Termo de Ajustamento de Conduta - TAC, no âmbito do Ministério Público brasileiro, no exercício do poder disciplinar, 15.5.2018.

BRAZIL, Tribunal de Contas da União. Acórdão nº 2.533/2017. Plenário. Relator: Walton Alencar Rodrigues. Sessão de 14/11/2017. Diário Oficial da União, Brasília, DF.

BRAZIL, Tribunal Regional Federal da $2^{\mathrm{a}}$ Região, $6^{\mathrm{a}}$ T., AC n. 0132722-04.2015.4.02.5101, Rel. Des. Poul Erik Dyrlund, j. 30/08/2017.

CARVALHO FILHO, José dos Santos. Manual de Direito Administrativo. 32. ed. rev., atual. e ampl. São Paulo: Atlas, 2018. 
FRANÇA, Vladimir da Rocha. Invalidação administrativa na Lei n. 9.784/99. Revista de Direito Administrativo, Rio de Janeiro, v. 225, jul./set. 2001.

GUARDIA, Gregório Edoardo Raphael Selingardi. Princípios processuais no Direito Administrativo Sancionador: um estudo à luz das garantias constitucionais. Revista da Faculdade de Direito da USP, São Paulo, v. 109, jan./dez. 2014.

HÄBERLE, Peter. Öffentliches Interesse als juristisches Problem. Eine Analyse von Gesetzgebung und Rechtssprechung. Bad Homburg: Athenäum, 1970.

JUSTEN FILHO, Marçal. Curso de Direito Administrativo. 13. ed. rev., atual. e ampl. São Paulo: Thomson Reuters, 2018.

MARQUES NETO, Floriano de Azevedo; CYMBALISTA, Tatiana Matiello. Os acordos substitutivos do procedimento sancionatório e da sanção. Revista Brasileira de Direito Público, Belo Horizonte, ano 8, n. 31, out./dez. 2010.

MARRARA, Thiago. Acordos de Leniência no Processo Administrativo Brasileiro: Modalidades, Regime Jurídico e Problemas Emergentes. Revista Digital de Direito Administrativo, v. 2, n. 2, 3 jul. 2015.

MEDAUAR, Odete. O Direito Administrativo em evolução. $2^{\text {a }}$ ed. rev., atual., e ampliada. São Paulo: Editora Revista dos Tribunais, 2003.

MEDAUAR, Odete. Direito Administrativo Moderno. 21. ed. Belo Horizonte: Fórum, 2018.

MOREIRA NETO, Diogo de Figueiredo. Curso de direito administrativo: parte introdutória, parte geral e parte especial. 15. Ed. Rio de Janeiro: Forense, 2009.

MOREIRA NETO, Diogo de Figueiredo. Novos institutos consensuais da ação administrativa. Revista de Direito Administrativo, Rio de Janeiro, v. 231, jan./mar. 2003.

Quatro paradigmas do Direito Administrativo. Belo Horizonte: Fórum, 2008.

NEVES, Cleuler Barbosa das; FERREIRA FILHO, Marcílio da Silva. Contrapesos de uma Administração Pública consensual: legalidade versus eficiência. Interesse Público - IP, Belo Horizonte, ano 19, n. 103, maio/jun. 2017.

OLIVEIRA, Gustavo Justino. Governança Pública e Parcerias do Estado: novas fronteiras do direito administrativo. Revista da Procuradoria Geral, Rio de Janeiro, Edição Especial, 2012.

OLIVEIRA, Rafael Carvalho Rezende. Agências reguladoras, diálogos institucionais e controle. Revista de Direito Público da Economia - RDPE, Belo Horizonte, ano 13, n. 49, jan./mar. 2015.

PALMA, Juliana Bonarcosi de. Atuação Administrativa consensual: Estudo dos acordos substitutivos no processo administrativo sancionador. 2010. 332f. Dissertação (Mestrado em Direito) - Faculdade de Direito da Universidade de São Paulo (USP), São Paulo. 
RODRIGUES, Marco Antônio dos Santos. Neoconstitucionalismo e legalidade administrativa: a juridicidade administrativa e sua relação com os direitos fundamentais. Revista de Direito Procuradoria Geral, Rio de Janeiro, v. 63, 2008.

SCHIRATO, Vitor Rhein; PALMA, Juliana Bonacorsi de. Consenso e legalidade: vinculação da atividade administrativa consensual ao direito. Revista Brasileira de Direito Público RBDP, Belo Horizonte, ano 7, n. 27, out./dez. 2009. Disponível em: <http://www.bidforum.com.br/PDI0006.aspx?pdiCntd=64611 >. Acesso em: 10 dez. 2019.

SILVA, Gabriel Cozendey Pereira. Indefinição conceitual acerca do dever constitucional de eficiência administrativa. Interesse Público - IP, Belo Horizonte, ano 18, n. 96, mar./abr. 2016.

SOUZA, Guilherme Carvalho de. A liberdade de contratar para a administração pública: a autonomia da vontade no contrato administrativo. Revista de Direito Administrativo, Rio de Janeiro, v. 260, maio/ago. 2012.

TESHEINER, José Maria; PEZZI, Sabrina. Inquérito Civil e Compromisso de Ajustamento de Conduta. Revista de Direito Administrativo, Rio de Janeiro, v. 263, mai. 2013. ISSN 22385177.

ZAPELINI, Marcello Beckert. Ética e Administração Pública: Uma abordagem a partir de Três Modelos Normativos. In: XXXVII Encontro da ANPAD. Rio de Janeiro, 7 a 11 Setembro de 2013.

Data de Submissão: 05/04/2020

Data de Aceite: 09/05/2020 